of extreme exacerbation of the neuralgia. In Dr. Barker's cases the operation was performed during a period of comparative freedom from pain. Brief summaries of the histories preceding the operative period are as follows:

Cass 1.-James W., 63 years of age, entered the hospital Aug. 2, 1899. He had been a sea captain by profession until the onset of his right-sided neuralgia, from which he had suffered for ten years. The pain occurred originally in the third division of the trigeminus. In July, 1896, and again in June, 1897 , two peripheral operations with evulsion of the infraorbital and inferior dental nerves had failed to give him more than a few weeks of respite from pain. For the two years before entrance he had been bed-ridden, and his sufferings had had no remission. At the time of operation his extreme paroxysms occurred every minute and $a$ half on an average, and with only slight relief during the intervals. His chief point of radiation of pain was just below the outer corner of the mouth. From there the pain spread into the territory of all three divisions of the $\mathrm{N}$. trigeminus during the paroxysms, to terminate at a point near the parietal eminence. The ganglion is shown in the accompanying photograph (Fig. 5).

Case 2.-W. E., 55 years of age, entered the hospital Dec. 17,1899 . He had been a business man until neuralgia interrupted his activities. He had suffered from pain, which appeared primarily in the distribution of the infraorbital branch, for twelve years. In 1892 the infraorbital nerve was evulsed,

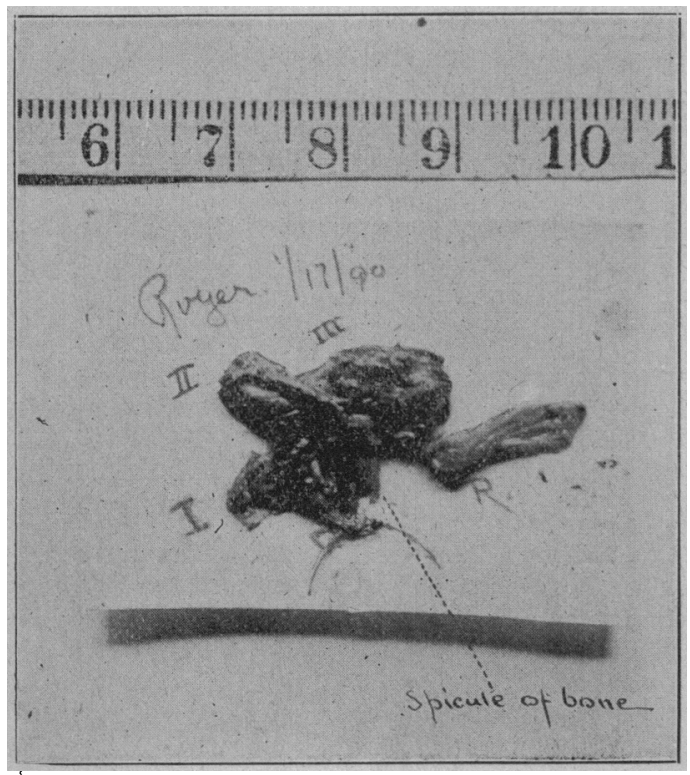

Fig. 8. Specimens from Case 4. (Dr. Barker). A spicule of bone is shown driven firmly into the ganglion, which was not removed in a good state of preservation. The sensory root $(\mathfrak{R})$, (N. trigeminus) tore away fron the ganglion during extraction and was subsequently removed. Photograph taken after hardening in formallin.

with relief for several months. On the return of pain, the inferior dental became involved, and subsequently the supraorbital region and pain finally extended to the territory innervated by the suboccipital nerves. His sufferings for several months before entrance were such that he had been in confinement and, on admission to the hospital, he was practically maniacal. His chief pain point from which the paroxysms radiated was situated in the right nasolabial fold. His sufferings were continuous, with exacerbations every few moments, or consequent on the slightest peripheral stimulus. The ganglion and branches are shown in the accompanying photograph (Fig. 6).

CASE 3.-A. D., 38 years of age, a shoemaker by trade, entered the hospital in January, 1900, having suffered from trifacial neuralgia for only two years. The onset was attributed to exposure and pain, and was at first limited to the supra. orbital area. One year later the infraorbital region became involved and soon the whole territory of the third division, the pain during the paroxysms extending into the suboccipital region. In March, 1899, by peripheral operations, I evulsed an inch or two of the inferior dental and infraorbital nerves, which showed the usual histologic changes after being re- moved. After relief for eight months the pain returned-November, 1899-with renewed vigor. The paroxysms at the time of entrance were not frequent nor very severe. The pain spread downward from the supraorbital division into the territory supplied by the second and third branches. The patient was operated on during this interval of comparative freedom. The ganglion is shown in Fig. 7 .

CaSE 4.-Elizabeth R., 60 years of age, had suffered for seven years from left-sided tic-douloureux, which originated in the superior maxillary branch of the trigeminal nerve, and was attributed to exposure. The definite point of origin of her paroxysms had always been situated near the ala of the nose. In August, $1897,5 \mathrm{~cm}$. of the infraorbital nerve was evulsed (Cushing) from the floor of the orbit. The nerve histologically showed the usual degenerative changes. Relief ensued for sixteen months, after which interval, with the return of pain the first and third divisions became invaded. In June, 1899, the regenerated nerve from the same situation was again evulsed (Mitchell) with subsequent relief for only four months. In January, 1900, the ganglion and roots were removed in toto, though with considerable difficulty and not in a good state of preservation. (Cf. Fig. 8.) The operation was performed during a period of comparative freedom from pain. (This symposium will be concluded next week.)

\section{MEDICAL ETHICS AND MEDICAL JOURNALS.*}

BY P. MAXWELL FOSHAY, M.D. EDITOR, CLEVELAND JOURNAL OF MEDICINE. CLEVELAND. OHIO.

To most of us the average paper concerning our intraprofessional relations is somewhat tiresome. In many quarters the dignity of medical ethics has been most loudly preached by those lacking experience in its practice. It is little to be wondered at, therefore, that the subject is not a popular medical society topic. Despite this acknowledged fact, I have determined to present some desultory thonghts concerning a subject that seems to me to be so important to the welfare of medicine as to deserve most earnest consideration. Duty may not be shirked because it is unpleasant.

Physicians are to-day face to face with many vital questions that can not be indolently ignored. Sapping professional honor to its very vitals is the matter of the giving of commissions for referred cases by the specialist to the general practitioner, involving as it does the points as to whether medicine is a profession or a trade, and as to whether our patients are sentient beings or mere purchasable and transferable commodities. From this and other problems the present paper turns to some consideration of the shocking abuses that have sprung up in the realm of medical journalism. Even as the specialist, from greater opportunity, is permitted to assume the possession of superior knowledge and experience in his chosen branch, so may, perchance, the medical journalist be permitted to offer some expert testimony as to the evil tendencies that he is forced constantly to observe.

The profession is not alive to the damage that it is suffering in the eyes of the world by reason of the present degradation of American medical journalism. Âs peoples, races and communities are judged by their literature, so is the profession of medicine perforce judged in large measure by its books and its journals, especially the latter, because it is presumed that they more accurately reflect the sentiment of the average readers. Admittedly the topic is not new, but honest facts will bear restating.

There are now published in this country some $\mathbf{2 5 0}$ medical journals of all kinds. Does the profession demand so many? If not, why are they issued? and how do they live? Many-including some of the best known -are owned by great publishing houses that are frankly

*Read, by invitation, before the Northwestern Ohio Medical Associa tion, Dec. 7, 1899 
engaged in the effort to accumulate wealth, both directly from their journals and indirectly from the books and other wares that they therein advertise. In the management and course of these publications the profession has little or no voice. Their editors-while they are medical men-have often to submit their judgment of propriety in editorial conduct to the commercial exigencies of the owners. Other periodicals are owned openly or covertly by proprietary-medicine makers, and their object is too obvious to need expression. Still others-too many, in sorrow be it said--are conducted by men of our own profession, whose sole object is self-exploitation, and whose aim is not for an honorable paid subscription list, but for profitable consultation cases. Only a small proportion of our journals are conducted by high-minded men whose single aim is the upholding of the honor of medicine and the directing of professional thought toward elevated ideals. It will thus be seen that medical journalism is in a state of chaos. Close observation shows that there are few medical journals that can not be bribed into defrauding their readers in one way or another, and it is not alone the least among them that sin chiefly in this respect.

There being such a multiplicity of journals, few of them could live alone on their subscription receipts, and the pharmaceutic firms are appealed to for advertisements. The greed for advertising patronage leads the editor only too often to prostitute his pen or his pages to the advertiser, so long as he can secure the coveted revenue. So our journals are filled with articles and editorials containing covert advertisements of this and that remedy. So great has this abuse become that many drug houses-few of the better ones be it said to the credit of the trade-will not deal with a journal that does not, in the advertising contract, agree to publish, in addition to the advertisement in its proper place, and without extra compensation, certain advertising matter among its original articles or editorials. This trick the profession well knows, and already it shows signs of failing of its object, for the physician becomes disgusted with the journal that so demeans itself, and suspicious of the firm that can not be satisfied with placing its wares honestly before the profession in a frank advertisement. Happily also there are signs that the manufacturer is beginning to see whither this practice tends, and to fear the inevitable loss that will shortly follow, when the profession refuses to longer support the journals that thus soil their pages and deceive their readers, or to buy from firms that deal in deception.

In a clever editorial, the St. Paul Medical Journal for November, 1899, frankly divides journals and advertisers into two classes-the honest and the dishonest-and adds that the honest journal rigidly segregates its scientific matter from its advertising pages, and that the honest advertiser appreciates the value to him of space in the honest journal, as the means of attracting to his wares through a plain advertisement the best professional attention. This courageous editorial writer then says: "Granted the above standard of honesty is correct there are not a dozen honest medical journals published in the United States to-day." This statement is sweeping, but it is lamentably true. One of our leading journals has several times in the past year published as scientific matter papers concerning the merits of different proprietary articles, whose importance is far from deserving sich attention and whose qualities are much better described in an adrertisement. One of these papers was written by a well-known medical author and teacher, and was subsequently republished-to the chag- rin, let us hope, of its reputed author-among the advertising pages of a homeopathic journal. Naturally the St. Paul Medical Journal wonders how much the author was paid by the firm whose product was thus advertised, and also how much the journal received for the prostitution of its pages to commercial greed.

To-day most journals carefully refrain from expressing any opinion upon many of the important and disputed matters of personal conduct that appertain closely to the physician's life, and some even do not hesitate to vilify those few journals that dare to raise a voice in favor of honorable conduct.

The existence of evil tendencies, however, does not suffice for the sweeping condemnation of all that is. Conspicuous examples of the extraordinary commercial and moral success of journals that do not fear to speak the truth, nor hesitate to condemn that that is evil, while urging the desirability of clinging to that that is good, give rise to a well-founded conviction that immorality in journalism is not what the profession expects from its editors. There is a keen demand for clean ideals and for free condemnation of patent venality.

The flood of sample copies of cheap medical journals on the doctor's desk has become so irresistible that the legitimate journals are all but swamped in the undertow that leads to the waste-basket. Many careless physicians frankly state that there is little need of their subscribing for journals, when complaisant journalists will keep them well supplied with periodic literature free of all expense. The tide seems yet to be rising, as one new medical journal, through the naive statement of one of its advertising patrons, announces that during its first four numbers of existence it has guaranteed to deliver a copy of one issue to every one of the 125,000 physicians of the United States. Others asseverate that they possess suspiciously numerous thousands of paid subscribers, when one doctor who pays for the paper is extremely difficult to find. If any one of you will for a month keep tally of the number of sample copies of medical journals that reach your office, you will be astounded at the total. Yet the "sample copy" is not wholly reprehensible, for it furnishes the only means by which the reputable journal may indubitably submit its merits to your scrutiny. But the honest journal will not send you a "sample copy" of every issue, nor several copies of each issue, and the character of the "sample," as evident to even brief inspection will unequivocally determine whether the copy comes honestly seeking your support for a meritorious undertaking or sneaks into your office to delude the advertiser into the belief that you are a regular subscriber.

The foregoing cursory review of the present status of medical journalism leads naturally and logically to the question: "What is the proper aim of medical journalism?" On the answer to this question depends our conclusion as to the ethics of the problem in hand. Probably few physicians ever stop to consider the reasons for the existence of medical jovrnals, or to formulate, however loosely, the principles that should govern their conduct. To give what is hoped to be a clear answer to this question, to clarify the profession's vision in the premises, and to aid, if never so little, in educating the professional conscience to the appreciation of journalistic evils and of the remedies that may be applied to the existing unfortunate conditions, is the object of this paper. There are certain reasons for the existence of medical journals that are constant and unvarying, and-once appreciated-they render easy the application to all cases of the test of legitimacy and usefulness.

Medical journals should be conducted only for the at- 
tainment of the following objects: The prompt diffusion of medical knowledge, the furnishing of a ready means for the intercommunication of professional thought, the elevation of professional morals, the binding together of the medical profession into one harmonious organism, the representation of the best medical thought with the effort to raise the intellectual and moral qualifications of the entire profession to that level, and the extinction of sects and of all unreason in the art or science of medicine. The publication whose course does not conform to these standards has no excuse for existence. It is necessary, therefore, that physicians should know the earmark of the good and of the bad among medical journals, in order that intelligent and discriminating choice may be facilitated.

Like trees and men, medical journals may be distinguished by their fruit. First and foremost eschew instantly every journal that intermixes its original matter with advertisements-such journals are not conducted for any good purpose, and do not meet any of the indications given above as adequate reasons for existence. It is manifestly incumbent on reputable journals to furnish to their readers reliable information of the worth of new pharmacentic preparations; and not all proprietary remedies are to be ruthlessly and unreasoningly condemned. Nevertheless, beware of that journal that repeatedly publishes cheap reports of limited experience by unknown authorities with remedies that are rightly regarded by reputable physicians with more or less suspicion, because of secrecy of composition or brazenness of exploitation. Such reports and experiences are of no value to the profession, and only those dealing with reputable and ethical pharmaceuticals are worthy of attention. The drug makers will soon learn that the profession is not to be hoodwinked by paid puffs published as original articles in cheap journals. The day for receiving large returns from that method is happily nearly gone, but it should be hastened by all physicians unanimously refusing to read or to be influenced by such articles, or to receive further copies of the journals in which they appear. The application of this remedy will greatly reduce the number of "fake" medical journals. If the profession could only realize the extent to which medical editors are constantly beingimportuned - even threatened - to cheat their readers by publishing as original matter articles that have been purchased or cajoled from frail or recreant doctors, there would be no hesitancy in applying the above remedy whenever the diagnosis of depraved journalism was made. It is better not to take any journal that repeatedly publishes unscientific articles concerning wares that are advertised in its pages. Unfortunately also it is almost always safe to look askance on those journals that publish "clinical and therapeutic reports," clippings from other journals, and "reading notices" scattered throughout their reading pages. Clean journals either refuse to publish such matter or else plainly include it in their advertising pages.

The preference should always be given to journals that are owned and entirely controlled by medical men. Even though of necessity they often err, it is at least certain that those conducted by reputable physicians are not promoted for mere mercenary reasons. Journals that are supported by or connected with reputable medical societies are universally governed by only the highest motives, and are well deserving of professional favor. Inasmuch as some of the best scientific work, and nearly all the practical advances in medicine, are first reported to medical societies, it follows that the papers and discussions presented are of the very freshest and most definite interest to the profession, and that the prompt publication of this original matter is of unquestioned service to scientific medicine. Foremost in this class stands by right The Journal of THE AMerican MediCAL Association, whose national scope and well-recognized merits need no further mention. Other commendable instances of journals of this class will readily occur to your memory. They are deserving of your constant interest and cordial support. Their ascendancy, along with the few other really independent journals, will mean the extinction of disreputable journalism-a desirable end that can be obtained only through the discriminating favor of an awakened professional conscience--and will insure the occupancy by American medical science of a much higher plane than is possible under present conditions.

Know something about the character and reputation of the editor of the journal for which you subscribe. It is not in reason to expect a clean journal from the hands of a self-advertiser or of a man of doubtful reputation, nor on the other hand is it likely that a physician of good character will edit an immoral journal. Be discriminating in your choice of journals. If you accidentally subscribe for one that on trial proves to be venal and to be opposed to the best interests of the profession, stop it and refuse to receive further copies.

That medical journals are overnumerous and too frequently demoralized and virtueless is in the main the fault of the profession, for if these papers were not received and read they would soon, as they deserve, die of inanition. 'Therefore it follows that the remedy for the existing disgraceful state of the ethics of medical journalism lies in the hands of the great body of the profession. Just so soon as you refuse to in any way countenance the readily recognized indecent journals, just so soon will they die for want of pabulum, for advertisers will be quick to realize that neither covert nor open advertising will pay in journals thus rejected by an enlightened professional conscience. If you are unable to persuade the promoters of these journals to cease sending you copies, write a letter for publication in one of the better class of journals stating the facts of the case, so that both the disgraced profession and the depleted advertiser may plainly see what journals are in ill repute with the profession and endeavor to exist by doubly deceiving both reader and advertiser.

It is not to be hoped that the reforms urged in this paper may be accomplished in a day, but if, in this imperfect manner, the conscience of the profession is aroused by directing attention to some of the evils that afflict American medicine through the shortsighted cupidity of many of its journals, the writer will feel amply rewarded for his effort.

\section{CONGENITAI APHAKIA AND IRIDEREMIA* BY FLAVEL B. TIFFANY, M.D.}

PROFESSOR OF OPHTHALMOLOGY, UNIVERSITY MEDICAL COLLEGE. KANSAS CITY, MO.

Congenital aphakia is an exceeding rare anomaly, and is usually accompanied with other serious defects of the eye. The cases I report are of two brothers, aged 21 and 10. who visited my office Feb. 23, 1899. Advised' to see me by Dr. Waterman, of Wilson, Kans., they were brought by an older brother who was perfectly emmetropic, with vision of $20 / 20$ of each eye. This brother stated that there were seren children in the family. three of whom, one sister and these two brothers, had some trouble with their eves; also that the mother had

\footnotetext{
*Read before the Midland Ophthalmological Bociety.
} 